\title{
A Set of Heuristic Measurements for Evaluating the Inclusiveness of a Technology
}

\author{
K. Pitula and T. Radhakrishnan \\ Department of Computer Science and Software Engineering \\ Concordia University, Montreal, Canada
}

\begin{abstract}
At a high level of abstraction, 'social inclusion' can be defined as the extent to which an individual or community can fully participate in society and control their own collective destiny. There are large disparities in this, particularly in underdeveloped rural areas of the world. Information and communication technologies designed to address this disparity must take into account the many barriers in the use of technology that these communities face. We define an 'inclusive technology' as a technology which overcomes the barriers to using technology inherent within a given community and increases the opportunities available to that community. We propose a conceptual model and a set of heuristic measurements for examining the 'inclusiveness' of a technology with respect to a given community, and illustrate their use by applying them to two real-world projects. By proposing this model and set of measurements, we hope to achieve a better understanding of 'development projects' and create a systematic process and a framework to assist software engineers in designing and evaluating software based services intended to reduce the Digital Divide.
\end{abstract}

\section{Introduction}

In this information age, the ability to access and understand the right information in a timely fashion has become essential. There are significant disparities in the socioeconomic opportunities available to people in rural versus urban areas throughout the world, contributing to inequities in the ability to use Information and Communication Technologies (ICT) to access information and services [1]. New low cost technologies such as inexpensive computers, wireless connected hand-held devices, and open source software tools, offer possibilities for reducing this gap. However, experience has shown that simply providing access to technology is insufficient. What people need is the ability to make use of technology in order to engage in meaningful and gainful social activities in a sustainable manner [2]. We introduce the term 'inclusive technology' to emphasise this dual aspect of technology and its sustainable use for benefit. 
In recent years, numerous ICT projects have attempted to bring the benefits of technology to marginalised communities. While the literature is full of case studies describing the launch of pilot projects in optimistic terms, the lack of rigour in evaluating and monitoring many of these projects raises questions about their long term success and sustainability [3]. Experience indicates that technology designed for marginalized communities poses unique design challenges and requires a multidisciplinary approach [4]. Current efforts to develop a systematic framework for assessing such projects, such as the Digital Opportunity Index defined by the WSIS [5] or the IDRC guidelines [6], largely focus on measuring technology use in the population or the impact of technology on society at a macroscopic level.

In this paper, we tackle the design challenge by applying a software engineering approach to designing technology to bring sustainable, measurable benefits to a community. By the term 'technology' we refer to the complex combination of hardware, software, content, information accessibility and the social infrastructure that allows people to benefit from it. Drawing on theoretical frameworks and empirical results from sociology, rural development, and technology adoption, we investigate how a given community can 'appropriate' a technology and put it to its own beneficial use. We propose a parameterised, conceptual model and a preliminary set of heuristic measurements to assess a technology's 'inclusiveness', where 'inclusiveness' characterises to what extent a given community can use a specific technology to achieve its goals. We then apply this model to some actual, real-life projects described in the literature.

We believe that such a model would be useful to software engineers when designing a targeted software project to address issues pertaining to the Digital Divide. With our model we hope to achieve the following:

1. Develop a better understanding of the Digital Divide problem domain on a project by project basis by modeling the key concepts and their relationships and attributes.

2. Provide the basis for a theoretical model that can be used to share the positive and negative experiences of the ICT4D community.

3. Augment the software design process with a systematic sub-process for 'situation based analysis' of technology inclusiveness, and develop a framework to assist software engineers in designing technology for projects in the Digital Divide domain.

Inclusive technology. At a high level of abstraction, social inclusion can be defined as the extent to which an individual or community can fully participate in society and control their own destinies. Among the many motives for social interaction, our focus is on the need for information at the individual level, by people who live in and are influenced by a community. The ability to use the appropriate technology plays a critical role in this regard, and there are several recognised barriers to achieving it. These barriers consist of access to (a) the physical resources such as devices and infrastructure, (b) the digital information resources such as software and content, (c) the human resources which correspond to the skills people need to extract and apply knowledge, and (d) the social resources which refers to the broader social context in which the technology is applied [2]. However, simply addressing these barriers does not guarantee that a technology will be used by its intended users. According to the Unified Theory of Acceptance and Use of Technology (UTAUT) model, a technology must be perceived as beneficial, easy to use, and socially endorsed, with an adequate 
infrastructure in place to support its use [7]. To meet these objectives a technology must be relevant to the needs of the community, it must expand on existing knowledge and skills, and it must be affordable and sustainable. To be part of a sustainable cycle, the benefits that can be derived from using the technology must balance the costs. Such a technology that fits into and is compatible with its environment is considered 'appropriate' [1]. All of these factors must be taken into account for a software project to be successful.

Based on the above, we define an 'inclusive technology' as a technology which empowers community members to more fully participate in benefiting from the information services provided so as to make a difference in their decisions and their lives. What changes are beneficial will be specific to a community's needs and values, but in general will increase the opportunities available to the advantage of the entire community. The ability to use and benefit from the information services will vary depending on several factors. To give some examples of factors that would contribute to making a technology inclusive with respect to some community, if a device is affordable, if the infrastructure on which it relies is available, if the software and content are in the local language, if people have or can develop the skills to use it, and if it addresses a local need, then all of these factors would contribute to enabling that community to benefit from using that technology.

\section{Conceptual model of inclusive technology}

Our conceptual model of inclusive technology is based on Maslow's Theory whereby needs motivate human behaviour. Here we briefly describe the key concepts of our model. A more detailed description is provided in [8]. Based on the literature on rural development, we characterise the rural communities in which we are interested as follows $[9,10]$ :

- They are remote, making transportation and communications costs prohibitive

- Livelihoods of community members are largely based on subsistence activities

- Household incomes are low, at or below the poverty level

- Many communities have limited or no public services and utilities such as schools, health clinics, banks, government services, electricity, phone lines, etc.

- Most community members speak primarily local languages

- Schooling is limited, leading to low reading and writing skills

- Most community members have limited or no exposure to computer technology

According to our model, the rural environment in which a community is embedded largely shapes that community's socio-economic activity. This in turn largely determines that community's needs. A community is composed of individuals who are connected in one way or the other. Needs motivate an individual to identify goals whose achievement will result in a quantifiable or qualifiable gain, which is the motivating factor for undertaking that activity. Achieving these goals requires both knowledge and action. Acquiring that knowledge and acting upon it, both require a set of skills, resources and tools. We divide these latter into two disjoint subsets: ICT specific and non ICT specific. This is depicted in the Entity-Relationship diagram presented in Fig. 1. 


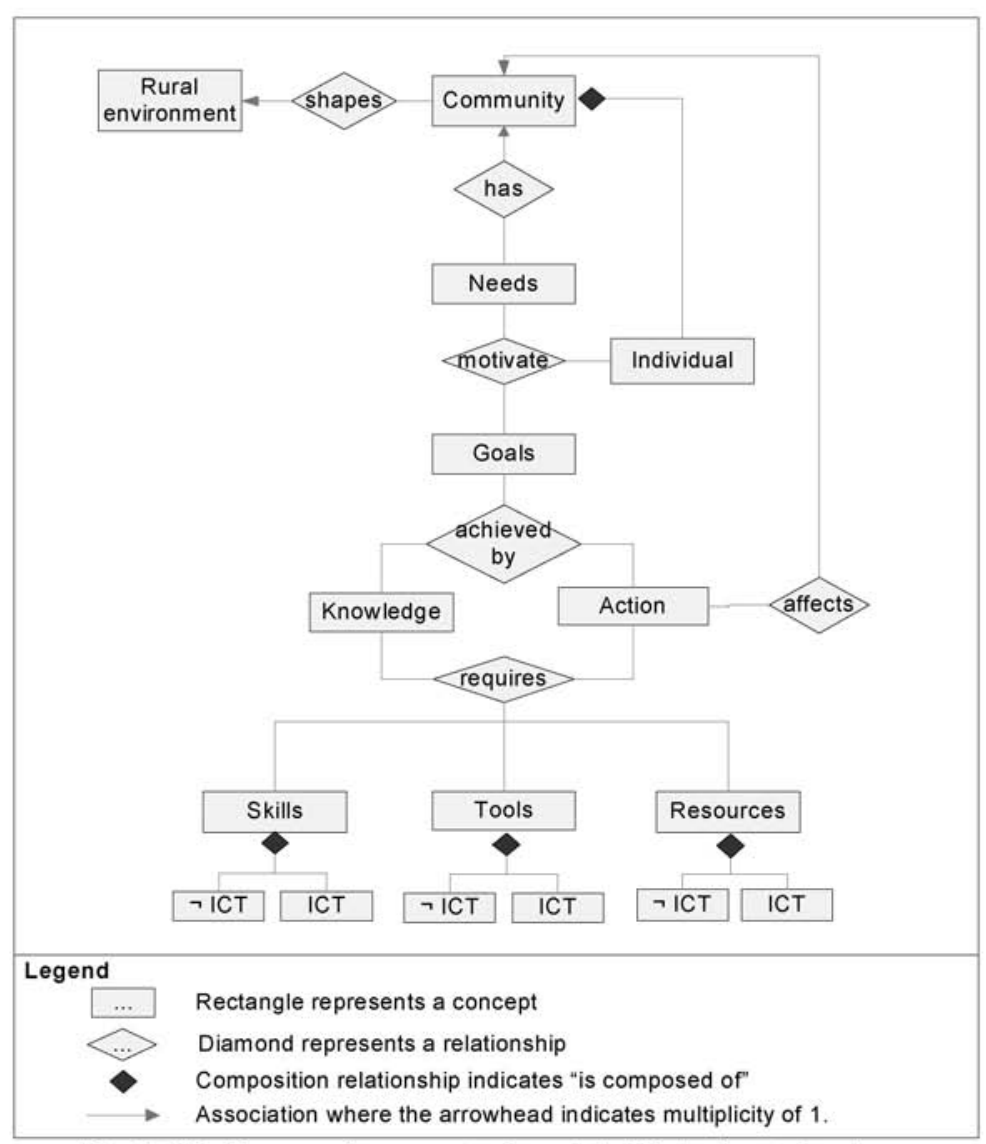

Fig. 1. ER diagram of a conceptual model of inclusive technology

Within this model, a sustainable cycle is achieved by selecting goals which result in a balance between social and economic benefits. This cycle can be described as follows: 'needs' stimulate the discovery of relevant 'knowledge' which leads to 'actions' resulting in 'benefits'. As the community's situation improves, its needs evolve creating more 'wants' stimulating the discovery of more relevant knowledge, and so forth. This process is illustrated in Fig. 2.

Our focus is on evaluating the ICT specific skills, resources, and tools to determine to what degree they support a community in developing the skills it needs to achieve its goals and improve its situation. Towards this end we associate certain attributes with each of the nodes in Fig. 1, based on our characterisation of the rural environment and the barriers to the use and acceptance of technology identified in [2]. These attributes are listed in the tables that follow. 


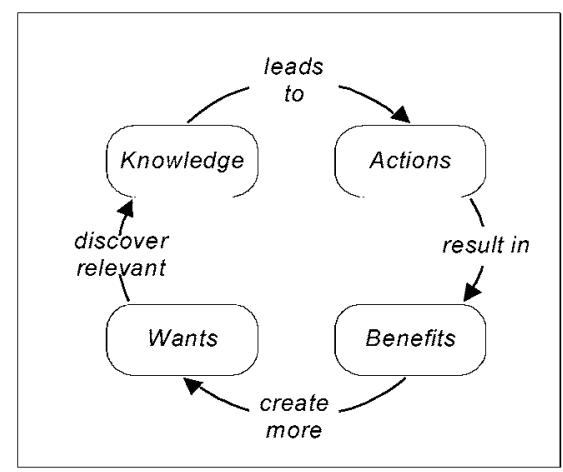

Fig. 2. Sustainable cycle

Table 1. Attributes of the environment and community

\begin{tabular}{|c|c|}
\hline Rural environment & Community \\
\hline $\begin{array}{l}\text { - population density } \\
\text { transportation and communications } \\
\text { networks } \\
\text { - distances to other communities and } \\
\text { urban centres } \\
\text { - climatic conditions affecting technology }\end{array}$ & \multirow{3}{*}{$\begin{array}{l}\text { - cost of transportation and } \\
\text { communications } \\
\text { - availability and cost of electricity, phone } \\
\text { lines, high-speed internet connections } \\
\text { - current economic and social activities } \\
\text { - organisations (political, community, } \\
\text { social, non-governmental, private } \\
\text { sector) } \\
\text { - services (schools, health clinics, } \\
\text { banking, government, etc.) } \\
\text { - sources of funding }\end{array}$} \\
\hline Individual & \\
\hline $\begin{array}{l}\text { - household income } \\
\text { - livelihood } \\
\text { - } \text { reading and writing skills } \\
\text { - compuages } \\
\end{array}$ & \\
\hline Need & Goal \\
\hline $\begin{array}{l}\text { - determined by the community and the } \\
\text { individual }\end{array}$ & $\begin{array}{l}\text { - defined by the community and the } \\
\text { individual to fulfill a need }\end{array}$ \\
\hline
\end{tabular}

Table 2. Attributes of the ICT tools, resources and skills

\begin{tabular}{|c|c|c|}
\hline ICT tools & ICT resources & ICT skills \\
\hline $\begin{array}{l}\text { - device } \\
\text { - } 1 / O \text { and peripherals } \\
\text { - } \text { cower sources } \\
\text { parts, maintenance \& } \\
\text { upgrades }\end{array}$ & $\begin{array}{l}\text { - } \text { content } \\
\text { - } \text { applications } \\
\text { training } \\
\text { peer support } \\
\text { - } \text { maintenance and updates } \\
\text { consultation }\end{array}$ & $\begin{array}{l}\text { - operate ICT tools } \\
\text { - access and create content } \\
\text { - run applications } \\
\text { - technical and } \\
\text { administrative support }\end{array}$ \\
\hline
\end{tabular}

\section{ICT heuristic measurements}

The set of measurements we propose here was developed and tested by applying them to a number of actual, real-life projects described in the literature [11-19]. To 
evaluate a given application of the underlying technology and the information services provided with respect to some community, the key questions to ask are:

- Is it feasible to deploy within the community's environment? This measures how practical it is to satisfy or adapt a technology's project requirements to the prevailing conditions and constraints within a given community.

- Is it affordable, cost-wise to the community? This measures the cost/benefit of the technology with respect to the community. It reflects to what extent the community and its members can afford to pay any costs and fees associated with the technology based services. Here, we only consider those costs that the community will be responsible for, either on an individual basis or as a group, in terms of acquiring, operating, maintaining, using and otherwise benefiting from the technology.

- Is it usable by the community? This measures both the standard usability metrics (effective, efficient, error-tolerant, easy to use, and engaging) and the physical accessibility of the software system with respect to the community of users. Accessibility looks at whether access is open to a critical mass of people in the community, including groups that might otherwise be marginalised for political, economic or social reasons.

- Is it relevant to the community's needs and goals? These measures how appropriate or significant the technology is to the community, given the community's needs and goals.

- Is it trustworthy? This measures how much trust the community can place in the technology. In other words, it measures if the community can rely on the tools, can trust the resources and can have confidence in the skills.

- Does it have the potential to improve and provide benefits to the community? These measures to what extent the technology can contribute to a positive and measurable outcome in line with the goals that the community has defined for itself.

- Does it advance the knowledge available within the community? These measures to what extent the technology adds to the body of knowledge that will enable the community and its members to act in the future.

These measurements are interrelated. A technology must be feasible, affordable, usable, relevant, and trustworthy for it to be able to lead to improvements or advances in knowledge. And any actual improvements can only be discovered after people have put the new knowledge they have acquired to beneficial action. In addition, for the technology to be sustainable, the improvements must balance the costs. A technology might be feasible, but at a cost that the community cannot afford. For example, although generator powered satellite connectivity can bring internet connections almost anywhere; few communities can afford this type of investment on their own. A technology might be feasible and affordable, but might be unusable by the community for many reasons; e.g. the community might lack the skills or language to use it. And even if it is usable, if it is not relevant to the community's needs and can not make a change, then there is little motivation to use it. On the other hand, if the technology is not trustworthy people will abandon it for a more reliable alternative. The following tables describe how each of these measurements is applied with respect to three dimensions: the tools, resources and required skills. 
Table 3. Measurements with respect to the ICT tools

\begin{tabular}{|c|l|}
\hline ICT tools & \multicolumn{1}{c|}{ Factors Considered } \\
\hline feasible & $\begin{array}{l}\text { - Can the required equipment and infrastructure be transported to the site? } \\
\text { - How will climatic conditions affect the operation of tools? } \\
\text { - Can parts, maintenance and upgrades be obtained in a timely fashion? } \\
\text { - Is there a location to house equipment? } \\
\text { - Is the infrastructure required to operate the tools available? } \\
\text { - Is there an organisation that can assume responsibility for managing and } \\
\text { maintaining the tools on-site? }\end{array}$ \\
\hline - Are the tools appropriate or can they be adapted to the local language and \\
skill set?
\end{tabular}

Table 4. Measurements with respect to the ICT resources

\begin{tabular}{|r|l|}
\hline ICT resources & \multicolumn{1}{c|}{ Factors Considered } \\
\hline feasible & - Can the resources be made available on-site either physically or \\
electronically? & - Will climatic conditions affect the availability of resources? \\
- How will the resources be administered, maintained and updated? & - How will distance affect maintenance and updates? Will distance affect \\
the ability of people to use the resources? & Is there a place where people can congregate to get training and share \\
their experiences and ideas? & $\begin{array}{l}\text { Are the applications, content and training program appropriate for or } \\
\text { adaptable to the local language and skill set? }\end{array}$
\end{tabular}




\begin{tabular}{|c|c|}
\hline affordable & $\begin{array}{l}\text { - Can the community afford the start-up and on-going costs for resources? } \\
\text { (i.e. software licenses, subscriptions, training materials, programs, etc.) } \\
\text { - Can individuals afford any costs associated with accessing the } \\
\text { resources? } \\
\text { - Can people afford to take the time away from their other activities? }\end{array}$ \\
\hline usable & $\begin{array}{l}\text { Does a critical mass of the population have access to the resources? Is } \\
\text { any group excluded? } \\
\text { - Are the resources available in the local language? } \\
\text { - Does the use of the resources require any special skills beyond current or } \\
\text { potential capabilities? } \\
\text { - Are the applications and content usable (i.e. effective, efficient, error- } \\
\text { tolerant, easy to learn and to use, and engaging)? }\end{array}$ \\
\hline relevant & $\begin{array}{l}\text { - Are the resources relevant to the community as a whole and its } \\
\text { individual members given current activities, practices, needs and goals? }\end{array}$ \\
\hline trustworthy & $\begin{array}{l}\text { - Can the resources be trusted to operate in a dependable and fail safe } \\
\text { manner? }\end{array}$ \\
\hline improvement & $\begin{array}{l}\text { - Do the resources contribute to a positive and meaningful outoome for the } \\
\text { community as a whole? For individual members? }\end{array}$ \\
\hline advancement & $\begin{array}{l}\text { Do the resources advance the knowledge available to the community? To } \\
\text { its individual members? }\end{array}$ \\
\hline
\end{tabular}

Table 5. Measurements with respect to the ICT skills

\begin{tabular}{|r|l|}
\hline \multicolumn{1}{|c|}{ ICT skills } & \multicolumn{1}{c|}{ Factors Considered } \\
\hline feasible & $\begin{array}{l}\text { - If specialised skills are required, is it feasible to make them available in } \\
\text { the community? } \\
\text { - Is it reasonable to expect people to have or develop the required skills, } \\
\text { given their background? }\end{array}$ \\
\hline affordable & $\begin{array}{l}\text { - Can the community afford the costs to develop or pay for the skills? } \\
\text { - Can individuals afford the costs to develop or pay for the skills? }\end{array}$ \\
\hline usable & $\begin{array}{l}\text { - Does everyone have access to someone with the necessary skills? } \\
\text { - Does everyone have access to the means of developing these skills? } \\
\text { - Can these skills be developed in an easy, effective, efficient, error- } \\
\text { tolerant and engaging way? }\end{array}$ \\
\hline relevant & $\begin{array}{l}\text { - Are these skills relevant to the community as a whole and individual } \\
\text { members, given current activities, practices, needs and goals? }\end{array}$ \\
\hline trustworthy & $\begin{array}{l}\text { - Does the community have confidence in the usefulness of the services } \\
\text { provided by the technology? }\end{array}$ \\
\hline improvement & $\begin{array}{l}\text { Do these skills contribute to a positive and meaningful outcome for the } \\
\text { community as a whole? for individual members? }\end{array}$ \\
\hline advancement & $\begin{array}{l}\text { Do these skills advance the knowledge available to the community? To } \\
\text { individual members? }\end{array}$ \\
\hline
\end{tabular}

Use of the Proposed Model: Our intentions in building this model are two fold: (a) to arrive at a set of measurable parameters in terms of which a technology's inclusiveness can be studied and then, (b) to study how the model can be used in both cases, namely in evaluating an existing project (technology) or in developing a new one. If a project is already operational, the metrics can be obtained based on 
experience and measurements; or if a new project is embarked upon, they can be estimated based on a 'situation based analysis' or from experience with similar projects.

When estimating, we believe that three different parameter values of low, medium, or high would be adequate. If a given measure is dependent upon unpredictable, external factors we assign it a "neutral" value. To give an example of value assignment, if the use of a certain technology requires face-to-face training of users, however the community in question is very distant with high transport costs, this will impact the feasibility and affordability of training for that technology, which will be reflected by a low rating for those measures on the skills dimension.

The measurements for a given dimension are combined by applying a MIN function. We infer that if an operational technology scores "high" on all measures, then it could be considered as highly inclusive. On the other hand, a technology which scores "low" on one or more measures will have potential sources of deficiency, and those aspects of the technology should be reworked. In the case of a proposed new project these high and low values could be treated as signals to decide what aspects of the design need to be improved before embarking on the project implementation so as to make the project a success. In this context, it is interesting to note from the literature that many funding agencies and other stakeholders involved in such projects find projects related to "ICT for rural Development" are either not evaluated or have no funds for evaluation, even though they all wish these projects to be successful [3].

\section{Examples of applying the measurements}

In this section we illustrate these measurements by applying them to two real-life projects described in the literature. In our first example, we look at a project to provide internet access in the Peruvian Amazon. The second is a project providing broadband access to remote communities in Canada. The evaluations we propose here are neither definitive nor absolute, but simply an outcome of our exercise based on the information available in the literature we accessed.

\subsection{Internet access in the Peruvian Amazon}

This was a telecentre project launched in 2000 , to bring internet access to a remote community in the Peruvian Amazon [13]. The community in question, Marakiri Bajo, is extremely poor, with a subsistence economy, no electricity and very limited basic social services. The program had strong supporters and many people had high expectations about the potential benefits. In the words of a local leader and project champion, "through the help of the internet indigenous peoples have the opportunity to overcome their exclusion and to have improved access to education, markets and political participation". Others were sceptical about the program's utility from the start. With external support, a technical solution was found to provide telephone and internet connectivity. As one of the key objectives was youth education, along with the telecentre, a state-of-the-art video-conferencing centre via a generator operated satellite system was installed. 
At first the project appeared very successful. Many people, including youth and women, began to explore the new technologies, and ICT training programs were launched. The youth quickly picked up skills, and several set up websites and made contact with other groups within the country and beyond. The program was hailed as a success and presented internationally. However, the project also ran into serious difficulties. For one, the centre was controlled by a small group and not open to the general public. As a result, many people within the community and neighbouring areas felt excluded from its potential benefits, aggravating tensions between different social groups. Secondly, many people had hoped that the centre would enable them to better sell their local produce. They were unable to realise this due to a lack of experience in e-commerce and the absence of on-line markets in Peru. Third, many people became disinterested because content was not available in the local language, and there was no information or services they could use in their daily lives. Finally, little benefit was drawn from the videoconference equipment due to the unavailability of educational programs and low demand.

A year after the centre was launched it mysteriously burnt down. After some serious reflection, the community relaunched its ICT program by opening a local radio station to broadcast programs of local interest in the local language. The closest internet access is now available in a telecentre located in a city at 2 hours distance. Our evaluation of the initial project is presented below.

Table 6. Evaluation of the Marikiri Bajo project

\begin{tabular}{|c|c|c|}
\hline & Score & Explanation \\
\hline ICT tools & low & $\begin{array}{l}\text { Overall score low based on low affordability, restricted access } \\
\text { and low relevance of the videoconference equipment. }\end{array}$ \\
\hline feasible & high & Generators and satellite connections are standard technologies. \\
\hline affordable & low & $\begin{array}{l}\text { Even if initial start-up costs are externally funded, on-going } \\
\text { costs to run generators and satellite connections are high when } \\
\text { compared to incomes in a subsistence economy. }\end{array}$ \\
\hline usable & low & Access to tools restricted to a small group. \\
\hline relevant & low & $\begin{array}{l}\text { The videoconference equipment has low relevance with respect } \\
\text { to the goals that community members would have liked to } \\
\text { achieve. }\end{array}$ \\
\hline trustworthy & neutral & $\begin{array}{l}\text { The tools will be reliable as long as the equipment is maintained } \\
\text { and fuel to run the generator is available. }\end{array}$ \\
\hline improvement & neutral & Potential to contribute to community improvement is neutral. \\
\hline advancement & neutral & Potential to contribute to community knowledge is neutral. \\
\hline $\begin{array}{l}\text { ICT } \\
\text { resources }\end{array}$ & low & $\begin{array}{l}\text { Overall score low based on unavailability of resources, } \\
\text { restricted access, and the lack of relevant content in the local } \\
\text { language. }\end{array}$ \\
\hline feasible & low & $\begin{array}{l}\text { The unavailability of educational programs, of an on-line } \\
\text { market, of content in the local language, and of local } \\
\text { information and services are very real and practical barriers. }\end{array}$ \\
\hline affordable & low & Access to resources restricted to a small group. \\
\hline usable & low & Lack of content in local language \\
\hline relevant & low & $\begin{array}{l}\text { The resources available did not support community expectations } \\
\text { i.e. information and services of local interest; better sales of }\end{array}$ \\
\hline
\end{tabular}




\begin{tabular}{|c|c|c|}
\hline & & local products, education in topics of interest \\
\hline trustworthy & neutral & Validity depends on the content consulted. \\
\hline improvement & low & Low relevance results in low potential for improvement. \\
\hline advancement & low & $\begin{array}{l}\text { Low relevance results in low potential for increasing } \\
\text { knowledge. }\end{array}$ \\
\hline ICT skills & medium & $\begin{array}{l}\text { Overall score of medium based on the benefit some individuals } \\
\text { were able to obtain by developing ICT skills. }\end{array}$ \\
\hline feasible & high & $\begin{array}{l}\text { The project showed that it was both feasible and possible for } \\
\text { members of the community to develop the necessary skills. }\end{array}$ \\
\hline affordable & high & We assume no costs were associated with developing the skills \\
\hline usable & low & We assume access was also restricted. \\
\hline relevant & medium & $\begin{array}{l}\text { Although the skills developed were not relevant to the } \\
\text { community as a whole, they were relevant to certain individuals. }\end{array}$ \\
\hline trustworthy & neutral & Confidence in the skills depends upon the individual. \\
\hline improvement & medium & $\begin{array}{l}\text { Although it did not apply to the whole community, certain } \\
\text { individuals did benefit from the skills they developed. }\end{array}$ \\
\hline advancement & medium & $\begin{array}{l}\text { Although not applicable to the whole community, certain } \\
\text { individuals were able to increase their knowledge. }\end{array}$ \\
\hline
\end{tabular}

Based on this evaluation we conclude that overall the technology in the initial project had low inclusiveness. Although it was feasible, the on-going costs to run a generator and satellite connection would have been unaffordable over the long term. The lack of relevant content in the local language as well as the inability to meet community expectations with the available resources gave it a low likelihood of resulting in any tangible improvements. The restricted access contributed to tensions within the community. On the other hand, although the technology in itself did not advance the available knowledge, the community's experience with the technology did, as reflected in the new priorities of the subsequent project.

\subsection{K-Net Services in Canada}

K-Net is a community network providing broadband service to 60 First Nation communities in northern Canada. Launched in the mid-90s, it has been the subject of many well documented studies $[11,12,16,19,18]$. The communities served are remote, small and in sparsely populated areas, with limited or no road access. Although most people speak English, Oji-Cree and Cree are the primary languages. For decades these communities experienced high unemployment, high suicide rates, and low school completion rates. In addition, most communities lacked basic health and school services, obliging members to fly great distances for medical treatment and schooling. In 1994, a council of Northern Chiefs in partnership with the government launched a regional broadband network called K-Net Services with the goal of promoting "economic development, social capital and civic participation". In the words of one of the founders, "if the internet is the information highway of the future, then our youth should be the drivers and not passengers".

The K-Net has a decentralised structure. K-Net Services negotiates with the different service providers to provide broadband services to the communities at wholesale prices. In turn each community owns, manages and maintains its own local network, buying services from K-Net according to community priorities, and 
offering them locally at an affordable price. Each community covers its connection costs by aggregating demand from band offices, schools, constabulary, nursing stations, businesses and subsidised on-line services along with individual use. A "champion" from the community represents local interests and is locally accountable. Champions are responsible for engaging the community in planning potential ICT projects and are involved in building support for projects at all levels in the community, government and with potential partners.

The initial service offering based on extensive consultation in the communities focused on telehealth and high school education. Since then a wide range of training and capacity building programs have been developed and delivered. Current services include video conferencing, telephony, VOIP, web and email services. Telehealth services in local nursing stations remain the most used and generate the most revenue, while VOIP provides $40 \%$ savings over standard long distance. There are currently over 38,000 email accounts and 18,000 group and hosting sites with free registration for First Nations and members of remote communities. In addition to broadband services, K-Net also provides technical training for local network managers and technicians, on-line support and a toll free help desk. It also runs workshops for youth in web page development and content management, and hosts various community and cultural web sites and discussion forums.

Table 7. Evaluation of the K-Net project

\begin{tabular}{|c|c|c|}
\hline & Score & Explanation \\
\hline ICT tools & high & $\begin{array}{l}\text { Overall score high based on high feasibility, affordability, } \\
\text { usability and trustworthiness. }\end{array}$ \\
\hline feasible & high & The equipment and infrastructure are standard technologies. \\
\hline affordable & high & $\begin{array}{l}\text { By prioritising goals and aggregating demand, can provide } \\
\text { service at an affordable price. }\end{array}$ \\
\hline usable & high & $\begin{array}{l}\text { Training of local management ensures that the tools are usable. } \\
\text { Access to tools does not appear restricted. }\end{array}$ \\
\hline relevant & neutral & Communities can select services according to their priorities. \\
\hline trustworthy & high & $\begin{array}{l}\text { The network and tools are well supported through training } \\
\text { programs and assistance. }\end{array}$ \\
\hline improvement & neutral & Communities can select services according to their priorities. \\
\hline advancement & neutral & Communities can select services according to their priorities. \\
\hline $\begin{array}{l}\text { ICT } \\
\text { resources } \\
\end{array}$ & high & Overall score high based on high score for all measurements. \\
\hline feasible & high & $\begin{array}{l}\text { Resources are designed for and made available to the } \\
\text { communities. }\end{array}$ \\
\hline affordable & high & $\begin{array}{l}\text { By prioritising goals and aggregating demand, resources are } \\
\text { offered at affordable prices. }\end{array}$ \\
\hline usable & high & $\begin{array}{l}\text { As the services are chosen by the community and designed for } \\
\text { these communities we assume that they are usable. }\end{array}$ \\
\hline relevant & high & $\begin{array}{l}\text { Communities select services according to their priorities. } \\
\text { Resources are designed based on consultation with the } \\
\text { communities and by community members themselves. }\end{array}$ \\
\hline trustworthy & high & Local management and accountability provide a basis for trust. \\
\hline improvement & high & Resources provided address community needs. \\
\hline
\end{tabular}




\begin{tabular}{|r|c|l|}
\hline advancement & high & $\begin{array}{l}\text { Resources provided with intent to increase the available } \\
\text { knowledge. }\end{array}$ \\
\hline ICT skills & high & Overall score high based on high score for all measurements. \\
\hline feasible & high & $\begin{array}{l}\text { Training and workshops are provided at no additional cost to the } \\
\text { community. }\end{array}$ \\
\hline affordable & high & $\begin{array}{l}\text { Training and workshops are provided at no additional cost to the } \\
\text { community. }\end{array}$ \\
\hline usable & high & $\begin{array}{l}\text { Training does not appear restricted, and the required skills are } \\
\text { available locally. }\end{array}$ \\
\hline relevant & high & Training addresses local needs. \\
\hline trustworthy & high & $\begin{array}{l}\text { Local management and accountability provide a basis for } \\
\text { confidence in the skills. }\end{array}$ \\
\hline improvement & high & Training addresses local needs. \\
\hline advancement & high & Training increases knowledge available to the community. \\
\hline
\end{tabular}

Based on the above we conclude that the technology is highly inclusive. The tools are highly feasible, affordable, usable and reliable. Training is provided to develop the required skills locally. The resources are designed with the intent to address the community's goals and increase the knowledge available at a local level.

\section{Conclusions}

In recent years, a growing number of software based projects have attempted to address the disparity in opportunities available to people in urban versus rural and underdeveloped areas of the world through technology. Some of these projects have been successful while others have failed. In this paper, we proposed a conceptual model that lays out the key factors involved in making an ICT based project inclusive with respect to some community, and a set of heuristic measurements for evaluating that technology's inclusiveness. We then apply this model to two projects that were already deployed and reported in the literature; and found that the model fits the findings reported. Our ultimate intention is to make this model useful to software engineers in different stages of the development cycle: requirements gathering, design, testing, deployment, and in on-going maintenance.

Acknowledgement: We thank the anonymous reviewers for their criticism and helpful references to the various ICT4D literatures relevant to our efforts. The preliminary model reported in this paper will be refined further for its future use.

\section{References}

1. Schumaker E.F. Small is Beautiful. Economics as if people mattered ... 25 years later with commentaries, Hartley \& Marks (1999).

2. Warschauer Marc. Technology and Social Inclusion, MIT Press (2003). 
3. Unwin, T. (ed.) ICT4D, Information and Communication Technology for Development. Draft retrieved 2007-02-24 from hitp://www.ict4d.org.uk/. To be published 2008 by Cambridge University Press.

4. Brewer E. Demmer M., Du B., Ho M., Kam M., Nedevschi S., Pal J., Patra R., Surana S. The Case for Technology in Developing Regions. IEEE Computer, Vol. 38, No. 6, 25-38. (June 2005).

5. World Information Society Report 2006. International Telecommunication Union (ITU). Retrieved 2007-02-23 http://www.itu.int/osg/spu/publications/worldinformationsociety /2006/report.html (2006).

6. Whyte, Anne Assessing Community Telecentres: Guidelines for Researchers, IDRC Books (International Development Research Centre). Retrieved 2007-02-21 http://www.idrc.ca/en/ev-9415-201-1-DO_TOPIC.html\#begining. (2000).

7. Venkatesh, Viswanath; Morris, Michael G.; Davis, Gordon B.; Davis, Fred D. User Acceptance Of Information Technology: Toward A Unified View. MIS Quarterly, Vol. 27 No. 3, pp. 425478 (September 2003).

8. Pitula, Kristina; Radhakrishnan, T. A conceptual model of inclusive technology for information access by the rural sector. To appear in $\mathrm{HCl}$ International $20(1) 7$ Conference Proceedings, Springer-Verlag. (2007)

9. Ashley, Caroline; Maxwell, Simon (principal authors). Rethinking Rural Development. Overseas Development Institute briefing paper reprinted in Current Issues in Rural Development, Swedish University of Agricultural Sciences, No. 3 1/32 (October 2003).

10. Reimer, Bill. Rural and Urban: Differences and Common Ground, in Urban Canada: Sociological Perspectives, ed. Harry H. Hiller, Oxford University Press (2005).

11. Beaton, B. The K-Net story: community ICT development work. The Journal of Community Informatics, Vol. 1, Issue 1 (2004).

12. Canadian Research Alliance For Community Innovation And Networking. K-Net Case Study Profile. Retrieved 2006-11-20 http://www3.fis.utoronto.ca/research/iprp/cracin/ research/K-Net\%20Case\%2()study\%2)Profile 2005.pdf (2005).

13. Gigler, Björn-Sörn. Including the excluded - Can ICT empower communities? Towards an alternative evaluation framework based on the capability approach. $4^{\text {th }}$ International Conference on the Capability Approach, University of Pavia, Italy. (2004).

14. Cecchini, Simone; Raina, Monica. Electronic government and the rural poor: the case of Gyandoot. MIT, Information Technologies and International Development, Vol. 2, No. 2, Winter (2004).

15. Garai, Atanu; Shadrach, B. Taking ICT to every Indian village: opporttnities and challenges. One World South Asia, New Delhi (2006).

16. Longford, Graham. Community Networking and Civic Participation in Canada: A Background Paper. CRACIN report prepared for The Department of Canadian Heritage. Retrieved 2006-11-20 http:/www3.fis.utoronto.ca/research/iprp/cracin/publications/ pdfs/wips/CRACIN_CNCP webversion.pdf. (2005)

17. Shaik. N. Meera, Anita Jhamtani, and D.U.M. Rao. Information and communications technology in agricultural development: a comparative analysis of three projects in India. Agricultural Research and Extension Network Paper No. 135 (2004).

18. Walmark, B., O'Donnell, S., and Beaton, B. Research on ICT with Aboriginal Communities: Report from RICTA, National Research Council Canada (2005).

19. Ramirez, R. A model for rural and remote information and communication technologies: a Canadian exploration. Telecommunications Policy No. 25, 315-330 (2001). 